\title{
Broad Band Propinquity Coupled Feed Line Micro- strip Blotch Antenna for 5G Applications
}

\author{
Haleema Sadiya, Harbinder Singh, Mamta Arora
}

\begin{abstract}
In this research based paper, as the need of capacity is increasing very frequently so the demand of smart mobile phone and other wireless communication devices are increasing. The only technology that would be able to fastly fulfill the increasing communication capacity is $5 G$. For the establishment of communication between the devices of wireless on the higher band of frequencies like $\mathrm{mm}$ wave (mili-meter) there is much demand of such type of antennas that are lesser in size, not much expansive, compact and also main easy to fabricate as well as simulate. So, according to all these requirements the antennas that can fulfill all the requirements are only the patch antennas. The Micro-strip blotch Antenna and the authentic viewpoint are shown with high gain millimeter-wave antenna. The micro-strip blotch Antenna has high gain more prominent ground as of late. The Antenna has a good return-loss, gain up-to $11.91 d B$ and the directivity $12.62 \mathrm{~dB}$ at $28 \mathrm{GHz}$ frequency with $6 \times 5$ micro-strip planar array configuration with Propinquity coupled planar array Feeding method \& line feed method procedure, it gives advantages over traditional conventional Antennas and benefits for $5 G$ applications. In this research work for the implementation the designing and simulation work done on CST TOOL. This simulation is basically performed for coup-led propinquity and line feed for $5 G$ application in future work together.
\end{abstract}

Keywords- Micro strip blotch Antenna (MPA), Return-loss, Feeding techniques etc.

\section{INTRODUCTION}

Antenna is an most important fundamental invention for remote applications. Underground bug that changes more than one structure into another and transmits or get the electromagnetic waves. Littler scale strip antenna contains oozing smear on one face of pass on electric ground-plane, real face and substrate. One more diminutive scale strip radio wire includes a rectangular fix on one side of ground plane parted by fail horrendously dielectric substrate [1]. Fix inside the transmitter device is made of an organizing element it can be Copper or Gold and these can adopt any state of rectangular, backhanded, triangle shape twisted or any corresponding customary design. Inside the fundamental structure, a micro strip blotch Antenna as appeared in Fig. 1 includes a transmitting smirch on a face of a fail miserably dielectric substrate and have a ground plane despite what might be expected side. The transmitting smear and the feed lines are generally photo scratched on the fail horrendously dielectric substrate [2].

Revised Manuscript Received on July 19, 2019

Haleema Sadiya, M.E student, Department of Electronics \& Communication Engineering, Chandigarh University, Gharuan.

Harbinder Singh, Professor, Department of Electronics \& Communication Engineering, Chandigarh University, Gharuan.

Mamta Arora, Professor, Department of Electronics \& Communication Engineering, Chandigarh University, Gharuan.

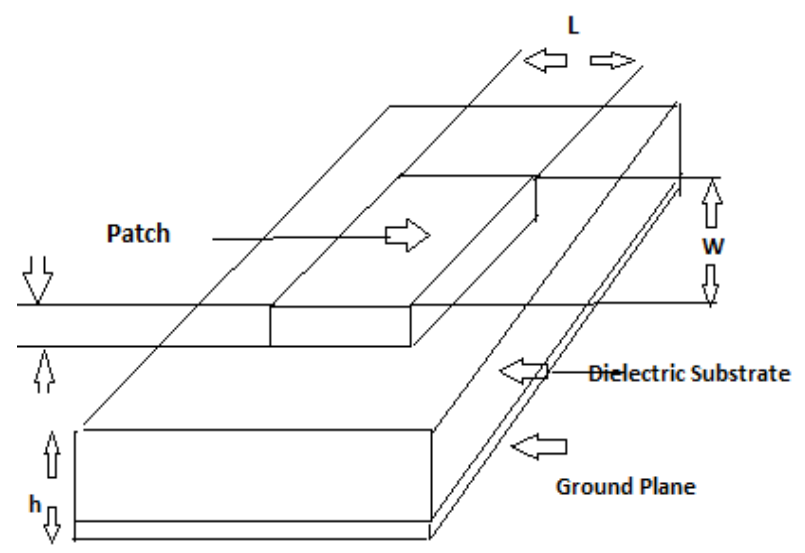

Fig.1. Micro strip Blotch Antenna

There are larger number of physical parameters in Microstrip patch antenna and a wide range of geometrical shapes and measurements. There are four classes: the classes are given below.

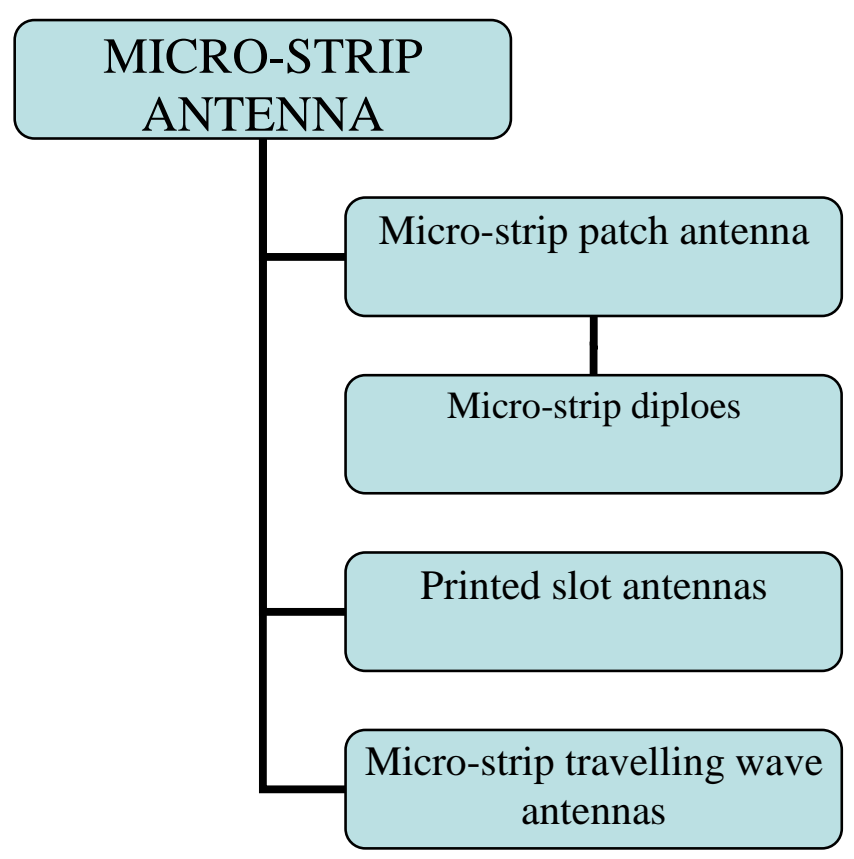

Fig.2. Micro strip Antennas categories

The Micro strip blotch antenna has double frequency agility, double and circular polarizations, recurrence nimbleness, costly band-width, Feed line adaptability, and also beam scanning omni-directional designing [2]. In [3] structure is proposed had the two band-width capabilities a series configuration and coupled Antenna that of a direct feed Antenna. The merits 
and demerits; micro strip patch antenna are very famous and favorites reduce weighted, profile, dimension, simplicity, congruity (Table I). It will help for planar based rectangular array pro-posed antenna. These antennas are helpful for $5 \mathrm{G}$ applications in future work which is based on satellite communications.

\section{TABLE I}

Advantages And Disadvantages

\begin{tabular}{|l|l|}
\hline \multicolumn{1}{|c|}{ Advantages } & \multicolumn{1}{|c|}{ Disadvantages } \\
\hline Reduce weight & Reduce efficiency \\
\hline less profile & Less gain. \\
\hline Thin profile & Large ohmic losses \\
\hline Required no cavity backing & $\begin{array}{l}\text { Low power handling } \\
\text { capacity }\end{array}$ \\
\hline $\begin{array}{l}\text { Linear and circular } \\
\text { polarization }\end{array}$ & Surface waves excitation \\
\hline $\begin{array}{l}\text { Equipped for both } \\
\text { operations: Double as well } \\
\text { as for triple frequency }\end{array}$ & $\begin{array}{l}\text { Purity of polarization } \\
\text { much hard to accomplish. }\end{array}$ \\
\hline $\begin{array}{l}\text { Coordinating system and } \\
\text { the lines of feed can be } \\
\text { fabricated. }\end{array}$ & $\begin{array}{l}\text { High performance of feed } \\
\text { is needed for complex feed } \\
\text { structure }\end{array}$ \\
\hline
\end{tabular}

\section{DIFFERENT FEEDING TECHNIQUES}

Many distinct systems for feeding little scale strip Antennas are there. These can be coming to and nonachieving techniques. In accomplishing strategy, RF control urged genuinely towards the radiating smear utilizing accomplice portion (littler scale strip line). In the non-achieving approach, control is exchanged between the littler scale strip line, also the radiating smear through electromagnetic coupling. Four strengthening systems are there: scaled down scale strip line and coaxial test (both accomplishing plans), opening coupling and closeness coupling (both non-achieving plans) [5].

- Micro-strip Line of Feed: Coordinating strip is attached really to the corner of the scaled down scale strip smear is little in measurement. Feed's benefit is that it may be scratched on similar substrate to give planar design [4].

- Coaxial Feed: Coaxial connector's inner conductor extends and attached with transmitting smear, also to the ground plane the outside conductor is coupled. Upside of this is it may be insert at any of the 26 zones in the fix so as to organize also with its information Impedance and also shortcoming moreover it gives confined transmission limit and is stunning to structure [6].

- Aperture Coupled Feed: The transmitting smear and scaled down scale strip line of field are restricted with the ground, also jointed through an opening in the ground face. Space is locked in underneath the smear, driving polarization of low cross also the radiations are constrained.

\section{LITERATURE SURVEY}

- K. Ming et. al.[7] Structured a 5G wideband patch antenna with anti symmetric L-formed Probe Feeds, in which a couple of hostile is used to symmetric L-molded tests \& it is vertically sandwiched in fix receiving wire and the proposed radio wire for double straight polarization is adequate to cover a wide working recurrence

- M.S. Sharawi et. al [8] Proposed four-component MIMO reception apparatus framework for $4 \mathrm{G} / 5 \mathrm{G}$ portable applications. The proposed plan is low profile, minimized and basic it additionally gives two-component MIMO framework to every standard. The incorporated radio wire framework is multiband and secured 1975-2080, 2160-2230, 2350-2620, 3060-3140, and 3480-3540 MHz for $4 \mathrm{G}$ groups and $16-17 \mathrm{GHz}$ band for 5G. MIMO execution measurements were determined with high addition and great proficiency esteems.

- J. Bang et. al [9] Presented a SAR (explicit assimilation rate) diminished $28 \mathrm{GHz}$ shaft guiding cluster reception apparatus with a double mode task utilizing two sub exhibits for completely metal secured $5 \mathrm{G}$ handsets. The proposed plan is demonstrated to have an adequate impedance coordinating, an adequate addition level, reasonable bar inclusion, and a diminished SAR level. The proposed exhibit radio wire is a decent possibility for the mm-wave $5 \mathrm{G}$ cell handset applications.

- L.H. Trinh et. al [10] Structured a reconfigurablemultiband receiving wire for the present portable models and expected range reallocations for $5 \mathrm{G}$ correspondence, This radio wire is utilized in cell phones, and particularly for different information various yield (MIMO) frameworks in which more than one reception apparatus must be coordinated in an extremely little volume.

- P. Dzagblete et. al [11] Presented a 42-component smaller scale strip parasitic fix receiving wire in the milli-meter-wave band for fifth-age (5G) portable correspondence base stations, The examination into the $\mathrm{mm}$ Wave recurrence band for $5 \mathrm{G}$ has been centered around different sign preparing improvements to discover the practicality of the band for cell correspondence. The $5 \mathrm{G} \mathrm{mm}$ Wave BSA (Base station reception apparatus) works inside 27.5 to $28.5 \mathrm{GHz}$ with SLL (side projection level) of $<-19.1 \mathrm{~dB}$, receiving wire gain of $>21.4 \mathrm{dBi}$, and cross polarization of superior to $-12 \mathrm{~dB}$ in both the planes

\section{DESIGN AND SIMULATION OF MICRO-STRIP PATCH ANTENNA}

Parameters for the designing of antenna: Here the parameters list of design of linear antenna array 
configuration is presented and also the dimension that are taken for the designing and simulation of micro strip patch antenna the width of patch, length of patch, thickness of substrate and ground[12], width \& length of ground $32 \&$ $47 \mathrm{~mm}$. .

TABLE II

PARAMETERS

\begin{tabular}{|l|l|}
\hline Symbol & Value(mm) \\
\hline $\mathrm{Pl}$ & 3 \\
\hline $\mathrm{pw}$ & 1.5 \\
\hline $\mathrm{Sx}$ & 0.6 \\
\hline $\mathrm{S}_{\mathrm{y}}$ & 0.5 \\
\hline $\mathrm{Sw}$ & 1 \\
\hline $\mathrm{S}_{\mathrm{l}}$ & 0.5 \\
\hline
\end{tabular}

Design of single element of array rectangular patch antenna (Fig.3) with the thickness of $0.508 \mathrm{~mm}$ each and two stacked Taconic TLY-5 substrates are used for designing $(\mathrm{Er}=2.2)$, length of patch $\left(\mathrm{pl}_{1)}=3\right.$, width of patch $\left(\mathrm{pw}_{1)}=1.5, \mathrm{sw}_{1=1}, \mathrm{sy}=0.5, \mathrm{sl}=0.5\right.$ (Table II).

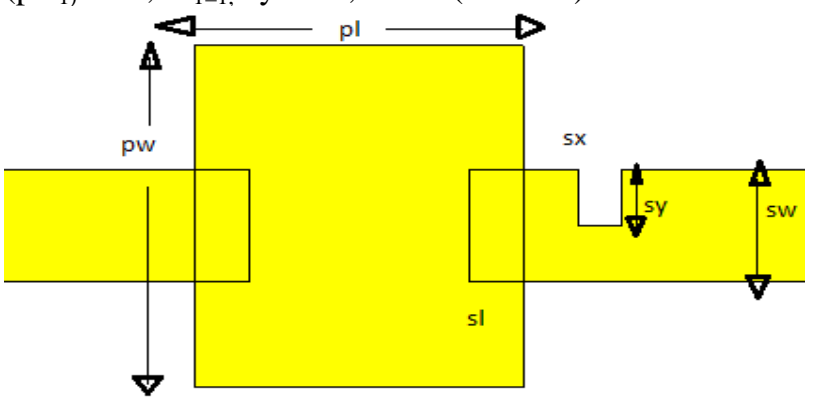

Fig.3. Design of linear element of array Antenna

A. Design and simulation of planar array configuration of the micro-strip patch antenna with proximity feed technique

By using the CST (computer simulation technology) tool the design of $6 \times 5$ planar array configuration of the microstrip patch antenna is simulated and the dimensions are in(Table III) . It is a $6 \times 5$ planar array configuration that means the combination of many antennas for the better result and efficiency, Now the simulation is done with a different technique i.e. proximity feed technique, in this technique two substrate are used and feed is applied in between them. The ground plane is made up of $\mathrm{Cu}$ (copper) material having thickness of 0.035 , the patch simulated at the top of the structure and it is made up of copper $(\mathrm{Cu})$ all the patches of array configuration's dimensions are shown Fig.5 (from CST tool), And there are two substrate are used, the substrate material is Taconic TLY-5 (lossy material), as this design simulation is of proximity technique so the feed is applied in between the two substrates the design is shown as in Fig.4.The six lines are symmetrical and separated by $\mathrm{s}=7.3$ to the feed-lines.

TABLE III

PARAMETERS

\begin{tabular}{|l|l|l|}
\hline Symbol & Value $(\mathbf{m m})$ & Description \\
\hline $\mathrm{t}$ & 0.35 & Thickness of ground \\
\hline
\end{tabular}

ISSN: 2278-3075, Volume-8, Issue-9S, July 2019

\begin{tabular}{|l|l|l|}
\hline Pw5 & 1.5 & Width of patch 5 \\
\hline Pw4 & 3 & Width of patch 4 \\
\hline Pw3 & 3.67 & Width of patch 3 \\
\hline Pw2 & 3 & Width of patch 2 \\
\hline Pw1 & 1.5 & Width of patch 1 \\
\hline P15 & 3 & Length of patch 5 \\
\hline P14 & 3 & Length of patch 4 \\
\hline Pl3 & 3 & Length of patch 3 \\
\hline Pl2 & 3 & Length of patch 2 \\
\hline Pl1 & 3 & Length of patch 1 \\
\hline h & 0.508 & Thickness of substrate \\
\hline
\end{tabular}

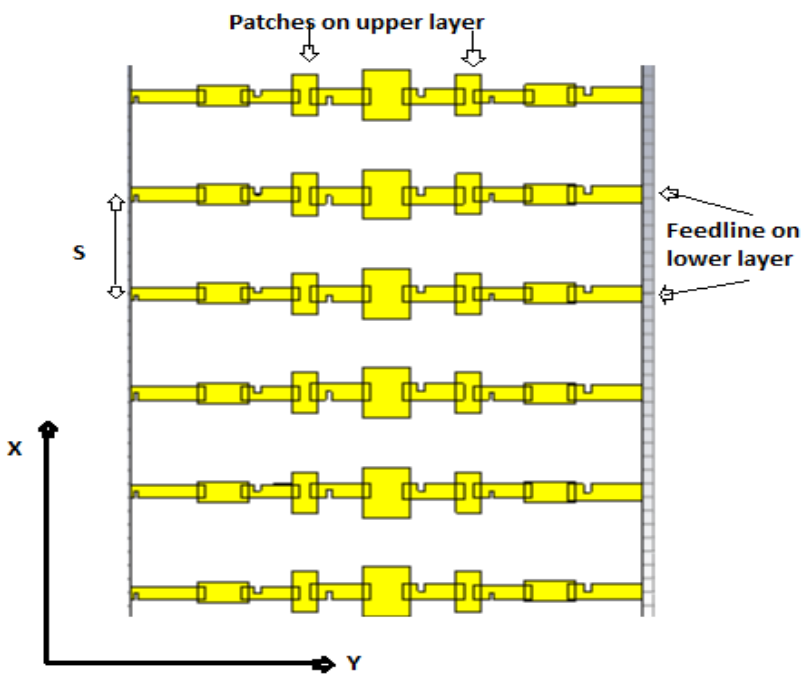

Fig.4. Design of planar array configuration with Propinquity Feed technique

Design of planar array configuration with proximity feed technique patches (Table III) on the upper layer are shown along with Feed-line on lower layer [Fig.4].

B. Result of planar array configuration of the microstrip patch antenna with proximity feed technique.

An epic insignificant exertion, high-gain millimeter-wave Projection is been shown. The $6 \times 5$ region coupled planar group fitting for $5 \mathrm{G}$ cell solicitations. Extra-ordinary comprehension among impersonated and assessed ouput comes that the analysed antenna structure is capable in achieving broad-band appearances and low side flap levels with a diminished size. From CST tool the results are shown further in below figures are of return loss, gain, directivity, VSWR.

\section{- The s-parameter simulation}




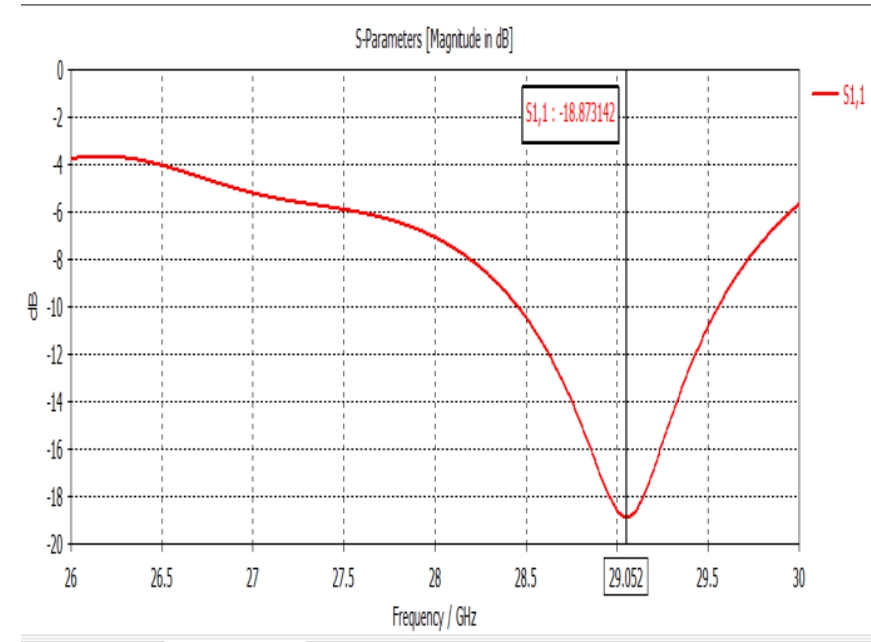

Fig.5. S-parameter at $29.05 \mathrm{GHz}$ frequency

The value should be less than $-10 \mathrm{~dB}$, the value of sparameter (Fig.5) achieved is $-18.87 \mathrm{~dB}$.

\section{- The 3D plot of directivity}

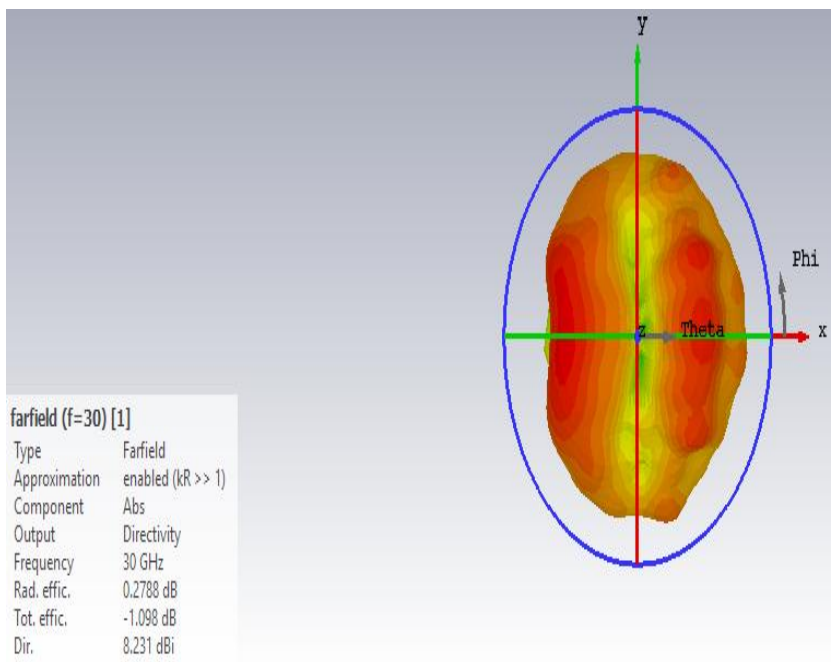

Fig.6. 3D plot of directivity at 30GHz frequency

The gain is achieved $8.231 \mathrm{~dB}$ at $30 \mathrm{GHz}$ frequency for planar array configuration (Fig.6)

\section{- The 3D plot of Gain}

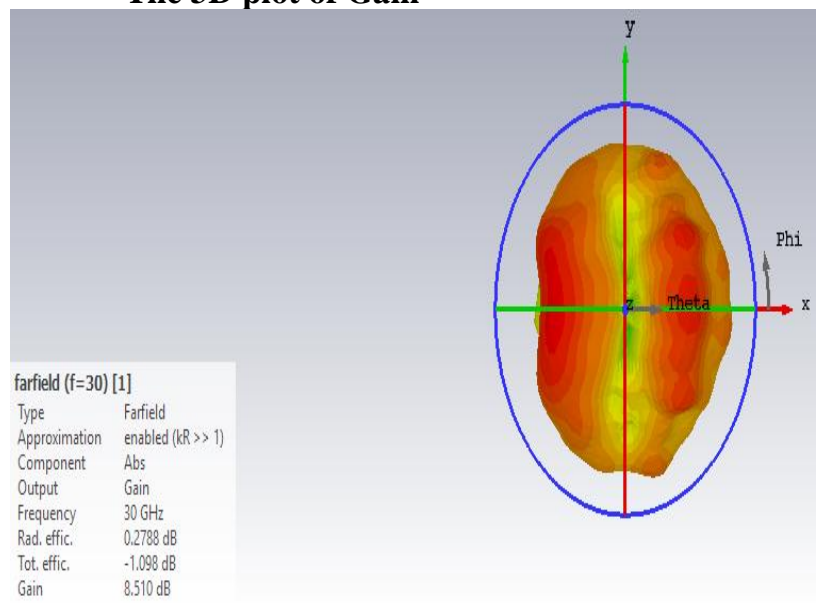

Fig.7. 3D plot of gain at 30GHz frequency
The gain is achieved $8.510 \mathrm{~dB}$ at $30 \mathrm{GHz}$ frequency for planar array configuration (Fig.7)

\section{- VSWR simulation}

Votoges Stanting Wave Ratio (SWWR)

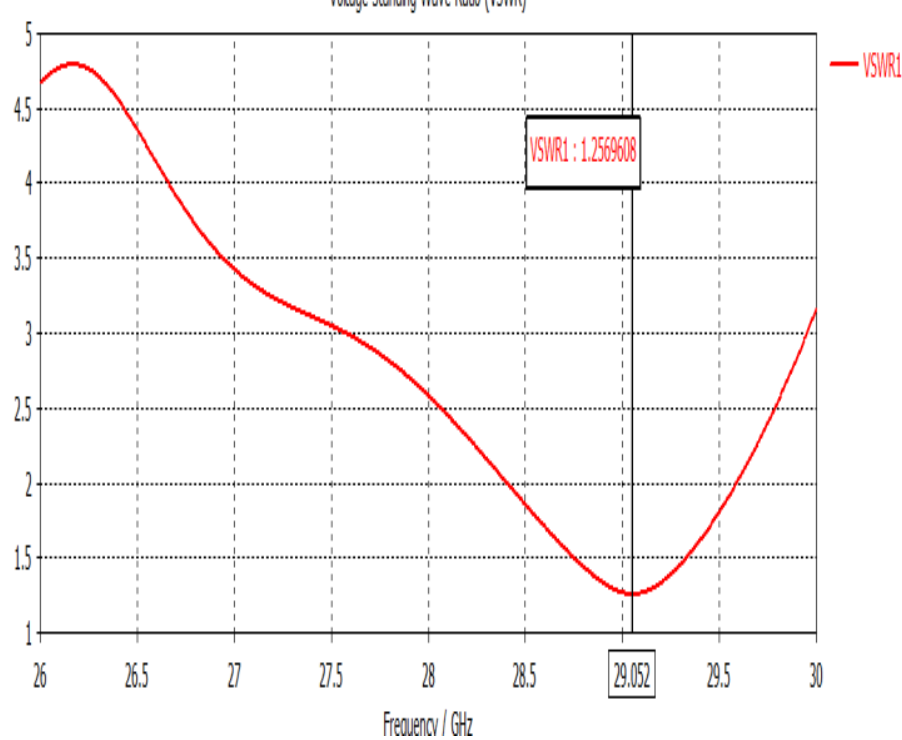

Fig.8. VSWR at 29.05GHz frequency

The value of VSWR should be less than 2, in simulated work (Fig.8) the value achieved is 1.25 at $29.05 \mathrm{GHz}$ frequency.

\section{MODIFIED RESEARCH WORK WITH LINE FEED METHOD}

Design and simulation of $6 \times 5$ planar array configuration of the micro-strip patch antenna with direct feed method instead of proximity feeding technique. Now for this method of direct feed one substrate is removed that means only one substrate will be used instead of two and the feed is direct applied to the design/simulation. The dimension's (Fig.4) sizes get reduced due to reduction in the thickness while designing by using only one substrate and the substrate material is Taconic TLY -5 the ground and patch are of $\mathrm{Cu}$ (copper) material.

A. Result of $6 \times 5$ planar array configuration of the micro-strip patch antenna with line feed technique.

By applying the micro-strip line feed technique instead of propinquity feeding method [12] on (Table III). Fig.4 structure and analysed outputs as; 


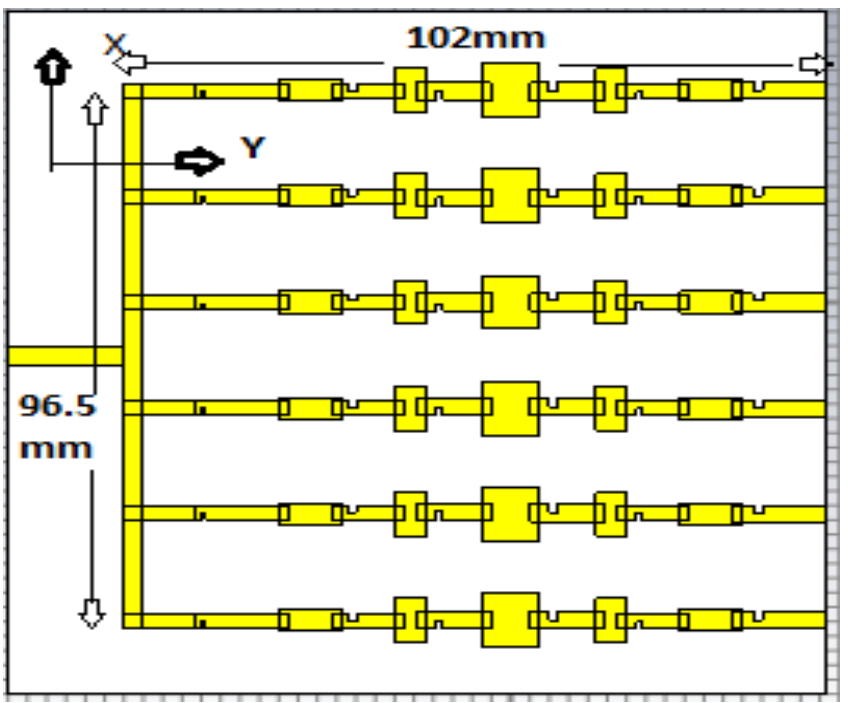

Fig.9. Design of planar array configuration of the micro-strip with line Feed technique structure

B. Result of planar array configuration of the microstrip patch antenna with line feed technique.

The simulation outcomes are shown further as how much gain is increased, the achievement of directivity of the proposed antenna, the VSWR (Voltage standing Ratio), the s-parameter value, all the simulation is done by using the parameters (Table III) and the designed for proposed micro-strip antenna (Fig.9) is simulated all work is simulated on a CST Tool.

- The result of s-parameter simulation

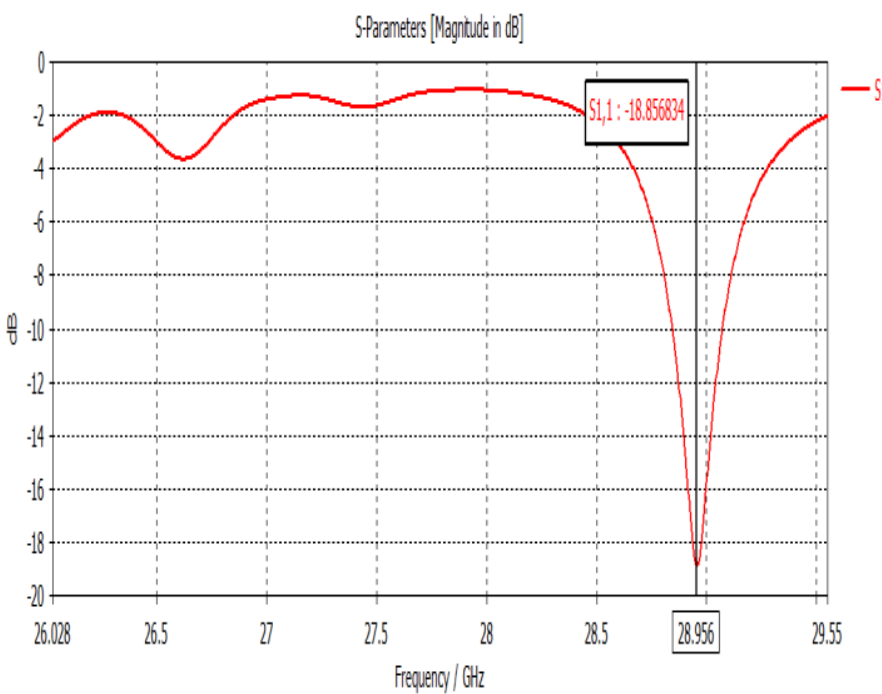

Fig.10. S-parameter at 28.956GHz frequency

The value should be less than $-10 \mathrm{~dB}$, the value of sparameter (Fig.10) achieved is $-18.85 \mathrm{~dB}$, and it is measured as the good value the gain and directivity values are ;

\section{- The 3D plot of Gain}

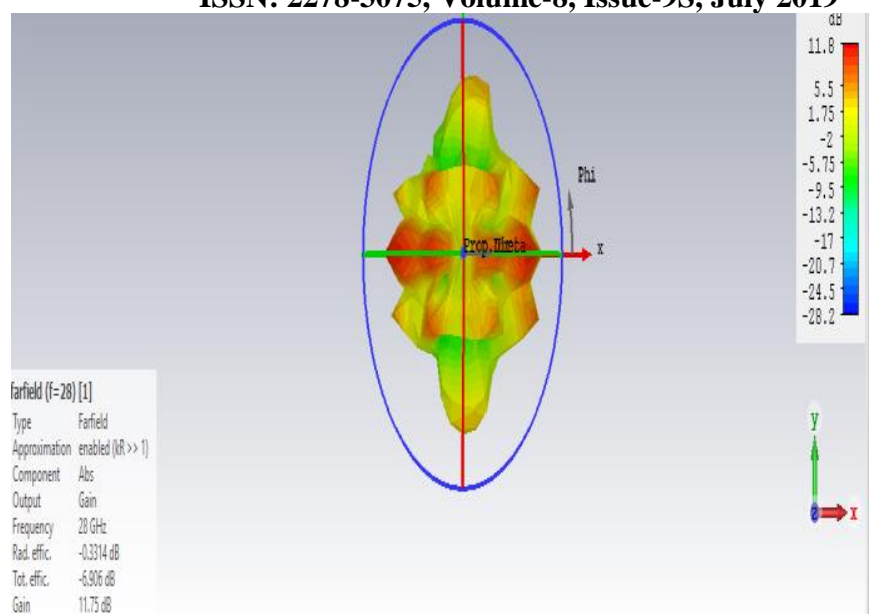

Fig.11. 3D plot of gain at $28 \mathrm{GHz}$ frequency

The gain is achieved $11.75 \mathrm{~dB}$ at $28 \mathrm{GHz}$ frequency for planar array configuration (Fig.11)

\section{- The 3D plot of directivity}

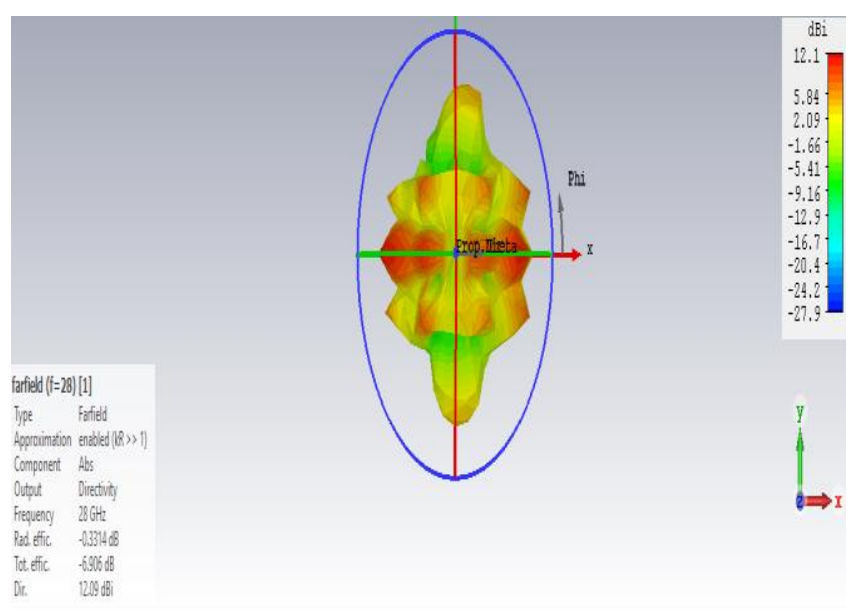

Fig.12. 3D plot of directivity at 28GHz frequency

The directivity is achieved $12.09 \mathrm{dBi}$ at $28 \mathrm{GHz}$ frequency for planar array configuration (Fig.12)

- VSWR simulation

Votoge Standing Wave Ratio (VSWUR

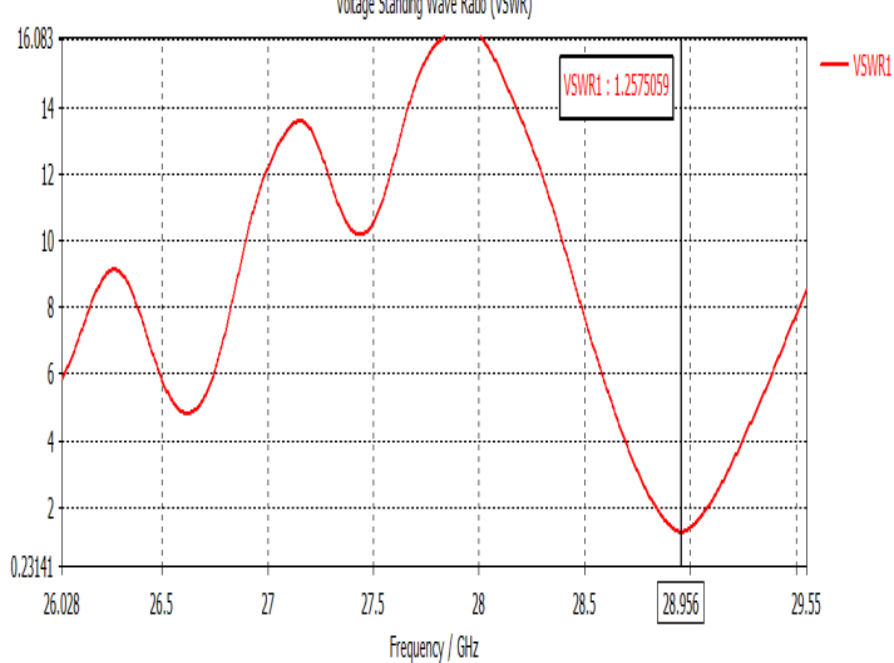

Fig.13. VSWR at 28.95GHz frequency

The value of VSWR should be less than 2, in simulated work (Fig.13) the value achieved is 1.25 at $28.92 \mathrm{GHz}$ frequency.
Published By:

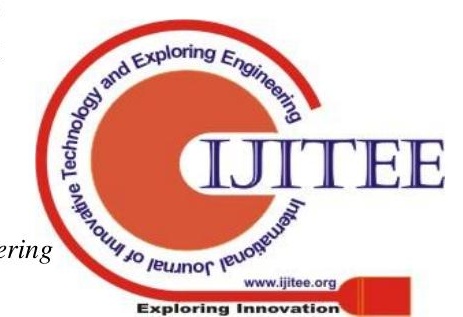




\section{E-FIELD AND H-FIELD}

The E field and $\mathrm{H}$ field are also shown here, according to the simulation of $6 \times 5$ planar array configuration of the micro-strip patch antenna with line feed method both fields (E Field and H Field) are also observed in this simulation at $26-30 \mathrm{GHz}$ frequency and simulated by CST software.

For the E-Field the main lobe magnitude is $9.88 \mathrm{dBv} / \mathrm{m}$, main lobe direction is $0.0 \mathrm{deg}$. With angular width $(3 \mathrm{~dB})$ is $11.1 \mathrm{deg}$ (Fig.14) with side lobe level $-2.1 \mathrm{~dB}$ and for the $\mathrm{H}-$ Field the main lobe magnitude is $-41.6 \mathrm{dBA} / \mathrm{m}$, main lobe direction is $0.0 \mathrm{deg}$. With angular width $(3 \mathrm{~dB})$ is $11.1 \mathrm{deg}$ (Fig.15) with side lobe level -2.1dB.

\section{- E-Field}

\section{Farfield E-Field $(r=1 m)$ Abs (Theta=90)}

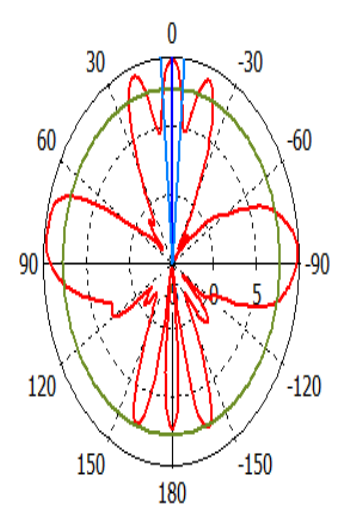

Phi / Degree vs. dBV/m
- farfield $(f=28)[1]$

Frequency $=28 \mathrm{GHz}$

Main lobe magnitude $=9.88 \mathrm{dBV} / \mathrm{m}$ Main lobe direction $=0.0$ deg. Angular width $(3 \mathrm{~dB})=11.1 \mathrm{deg}$. Side lobe level $=-2.1 \mathrm{~dB}$
Fig.14. E-Field at $28 \mathrm{GHz}$ frequency

\section{- H-Field}

Farfeld H-Field $(r=1 m)$ Abs (Theta $=90)$

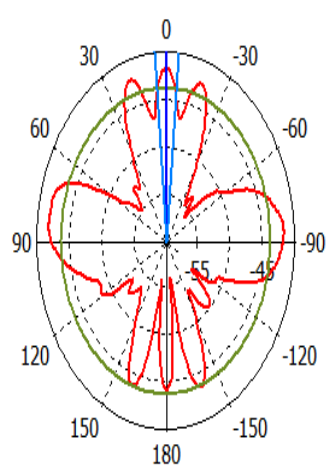

Phi / Degree vs. dBA/m
一 farfeld $(f=28)[1]$

Frequency $=28 \mathrm{GHz}$ Main lobe magnitude $=-41.6 \mathrm{dBA} / \mathrm{m}$ Main lobe direction $=0.0$ deg. Angular width $(3 \mathrm{~dB})=11.1 \mathrm{deg}$. Side lobe level $=-2.1 \mathrm{~dB}$
Fig.15. H-Field at 28GHz frequency

The angular width $(3 \mathrm{~dB})$ of planar array configuration of the micro-strip patch antenna with line feed technique work is near to $11 \mathrm{deg}$. in the E-field and $\mathrm{H}$-field and the half-power beam width is near to $15 \mathrm{deg}$. in the E-field and $\mathrm{H}$-field for planar array [13] configuration of the microstrip patch antenna with proximity feed technique.

\section{COMPARISON OF TECHNIQUES}

Comparison and simulation result of planar array configuration of the micro-strip patch antenna simulation with two different techniques:

- Proximity feed technique

- Line feed technique

Comparison shown as in the tabular form under(Table IV)

TABLE IV: COMPARISON OF TECHNIQUES

\begin{tabular}{|l|l|l|}
\hline $\begin{array}{l}\text { Micro-strip } \\
\text { patch antenna } \\
\text { array }\end{array}$ & $\begin{array}{c}\text { Micro-strip } \\
\text { patch array } \\
\text { antenna with } \\
\text { proximity feed } \\
\text { technique }\end{array}$ & $\begin{array}{c}\text { Micro-strip } \\
\text { patch array } \\
\text { antenna with } \\
\text { line feed } \\
\text { technique }\end{array}$ \\
\hline $\begin{array}{l}\text { Resonant } \\
\text { frequency }\end{array}$ & $26-30 \mathrm{GHz}$ & $26-30 \mathrm{GHz}$ \\
\hline s-parameter & -18.87 & -18.85 \\
\hline Gain & $8.510 \mathrm{~dB}$ & $11.75 \mathrm{~dB}$ \\
\hline Directivity & $8.231 \mathrm{dBi}$ & $12.09 \mathrm{dBi}$ \\
\hline VSWR & 1.25 & 1.25 \\
\hline
\end{tabular}

\section{CONCLUSION}

A design of a novel-Propinquity coupled micro-strip planar Antenna has been presented with low cost. It consists of high gain mm wave Antenna it gives the advantages over traditional microwave Antenna \& benefits for $5 \mathrm{G}$ applications. The proposed Antenna has Gain of over $11.75 \mathrm{~dB}$ with Directivity $12.09 \mathrm{~dB}$ at $28 \mathrm{GHz}$ with good Return-loss. The antenna can discover potential application for future wireless communication based antenna propagation determined. The structure of a novel coupled smaller scale strip planar antenna is proposed and manufactured. The designing depends upon an arrangement sustaining procedure that takes into consideration a tight planar cluster design to be effectively developed. These antennas are extremely valuable in applications where reduced dimensions noteworthy prerequisite. It might additionally be upgraded for staged cluster applications, the proposed $6 \times 5$ cluster has an angular width is very near to 11 deg. at $28 \mathrm{GHz}$ with an impedance data transfer capacity of $9.8 \%$. The soundness of the structure is outlined by the likenesses in the recreated and estimated outcomes, making it truly appropriate for combination in 5G applications. The design added with line feed technique that can be easily simulated and because of the results of this work like wide radiation pattern and good directivity it may considered as the efficient antenna having better efficiency, good return loss, good VSWR value as well achievement

\section{REFRENCES}

[1] R/M Barrett, "Microwave Printed Circuits The Early Years", IEEE Trans. Microwave Theory Tech., vo232, no. 19, Sept. 1987. 2, pp. 783-700.

[2] H.Howe, "Microwave integrated Circuits -An Historical Prespective:, IEEE trans.. Microwave Theory Tech., vol. 132, no.9, Sept. 1987. 3, pp. 91-96

[3] Y.B jung and H.A Diawuo "Wideband Propinquity coupled microstrip linear array design for 5G mobilecommunication", Microwave Opt.Tecnol.Lettl,vol.59,no.12,2 018, pp, .996-002.

[4] R .Z,W.Ling, T.Xiaobong, Z.Xinjing, "Study of micro-strip line inserted fed and two layer electromagnetically coupled rectangular blotch 
Ant-ennas," Microwave Conference Proceedings APMC, vol. 24 2000 .

[5] V singh, M thakur, "Band-width Enhancement of Microstrip line inset fed Path Ant-enna,"IJERT, vol 1.3, August- 2018.

[6] R. Verma, N. Vyas, R. Rana, V. Kaushik, A.K. Arya, 'Design study of Microstrip Antenna with Various Feeding Techniques: A Review, International Journal of Engineering Research \& Technology, 3, 2014, pp. 619-622.

[7] K.Mak, H.Lai and K.Luk. "A 5G Wideband Patch Ante-nna With Antisymmetric L-shaped Probe Feeds". IEEE Transactions on Antennas and Propagation, 66(2), pp.957-961, 2018.

[8] M. Sharawi, M. Ikram and A. Shamim, "A Two Concentric Slot Loop Based Connected Array MIMO Ante-nna System for 4G/5G Terminals". IEEE Transactions on Ante-nnas and Propagation, 65(12), 2017, pp.6679-6686.

[9] J. Ban G and J. Choi. "A SAR Reduced mm-Wave BeamSteerable Array Ante-nna With Dual-Mode Operation for Fully Metal-Covered 5G Cellular Handsets". IEEE Ante-nnas and Wireless Propagation Letters,17(6), 2018, pp.1118-1122.

[10] L. Trinh, F. Ferrero, L. Lizzi,R. Staraj. and J. Ribero. "Reconfigurable Ante-nna for Future Spectrum Reallocations in 5G communication" IEEE antennas and wireless Propogation Letters,15,2016, pp.1297-1300.

[11] P. Dzagblete and Y. Jung, "Stacked Micro-strip Linear Array for Millimeter-Wave 5G baseband Communication". IEEE Antennas and Wireless Propagation Letters, 17(5), 2018, pp. 780-783,.

[12] D. HA, J.Y-B. 'Wideband proximity coupled microstrip linear array design for 5G mobile communication' Microw Opt Technol Lett. 2017;59, pp. 2996-3002.

[13] H. Abu, Y. Bae a.,(2018). broadband proximity-coupled microstrip planar antenna array for $5 \mathrm{~g}$ cellular applications. ieee antennas and wireless propagation letters, 17(7), pp. 1286-1290.
ISSN: 2278-3075, Volume-8, Issue-9S, July 2019

\section{AUTHORS PROFILE}

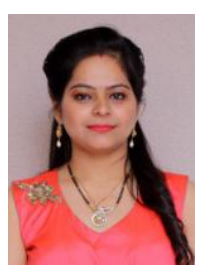

Haleema Sadiya received her B.tech degree in Electronics \& Communication Engineering from Baba Ghulam Shah University of Engineering Science \& Technology, Rajouri, Jammu \& Kashmir in 2017.She is currently a M.E. student at Chandigarh University, Punjab, India in the department of Electronics \& Communication since 2017, her areas of interest are antenna,5G.

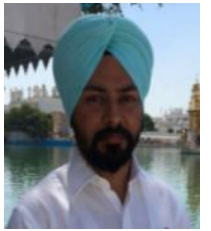

Harbinder Singh received his B.Tech \& M.Tech degree from the department of Electronics \& Communication Engineering from Haryana Engineering College and Punjab Technical University. $\mathrm{He}$ is currently working as Associate Professor in Chandigarh University.

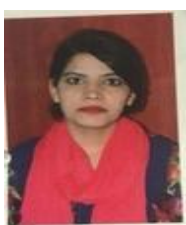

Mamta Arora received her B.Tech degree from the department of Electronics \& Communication Engineering from RIMT-MAEC mandigobindgarh. She completed her Masrter in Technology from Electronics department of Guru Nank Dev. She is currently working as Associate Professor in Chandigarh University. 